\title{
Atividade antifúngica do extrato natural da acácia-negra à Pycnoporus sanguineus
}

\author{
Antifungal activity of the black wattle natural \\ extract in relation to Pycnoporus sanguineus
}

\author{
Amanda Grassmann da Silveira1, Elio José Santini², \\ Stela Maris Kulczynski ${ }^{3}$ e Rômulo Trevisan ${ }^{3}$
}

\begin{abstract}
Resumo
Entre os organismos xilófagos, os fungos são os maiores responsáveis por grandes prejuízos na produção de madeira. $O$ uso de fungicidas químicos por tempo prolongado tem como implicação o surgimento de linhagens mais resistentes e a toxidez ao ambiente. O objetivo do presente trabalho foi avaliar o efeito fungitóxico do extrativo tanino derivado da Acácia Negra (Acacia mearnsii) sobre o crescimento micelial do fungo Pycnoporus sanguineus, causador da podridão branca. Três metodologias foram elaboradas para trabalhar com o produto (esterilizando, não esterilizando e filtrando) e quatro concentrações $(0,5 ; 1,0 ; 1,5$ e 2,0\%) foram individualmente incorporadas ao meio de cultura (BDA), avaliando-se o crescimento radial do micélio avaliados e comparados com a testemunha. $O$ procedimento se repetiu com a metodologia avaliada como sendo a mais adequada, porém aumentando as concentrações (3,0; 4,0 e 5,0\%). As concentrações de 4 e $5 \%$ mostraram-se as mais eficientes sobre a atividade fúngica, sendo que a segunda demonstrou inibição total em $50 \%$ das placas avaliadas, apresentando também o menor índice de crescimento micelial dentre todos os tratamentos testados.
\end{abstract}

Palavras-chave: tanino, decomposição, podridão branca, ensaio fungitóxico.

\begin{abstract}
Among the xylophagous organisms, fungi are mostly responsible for major losses in wood production. The prolonged use of chemical fungicides implies in the emergence of more resistant lines and toxicity in the environment. The goal of this study was to evaluate the toxic effect of the tannin extractive derived from the black wattle (Acacia mearnsii) on the mycelial growth of the fungus Pycnoporus sanguineus, causing white rot. Three methodologies have been developed to work with the product (sterilizing, nonsterilizing and filtering) and four concentrations $(0.5,1.0,1.5$ and $2.0 \%)$ were individually incorporated into the culture medium, evaluating the radial growth of the evaluated mycelium and results were compared with the non-treated specimen. The procedure was repeated with the methodology evaluated as being the most adequate, but increasing concentrations (3.0, 4.0 and 5.0\%). The concentrations 4 and $5 \%$ were more efficient to fungal activity, and the second showed total inhibition in $50 \%$ of the plaques evaluated, also showing the smallest mycelial growth rate among all treatments tested.
\end{abstract}

Keywords: tannin, decomposition, white rot, fungitoxic test.

\section{INTRODUÇÃO}

A madeira é um dos mais importantes e versáteis materiais da construção civil e do setor mobiliário e, por isso, desempenha um importante papel na economia mundial. No entanto, esse material é suscetível à deterioração causada por diversos agentes bióticos e abióticos (BROCCO et al., 2017) e exige atenção durante seu armazenamento, transporte, fabricação e aplicação (GONZÁLEZ-LAREDO et al., 2015).

Dentre os bióticos, o fungo xilófago denominado de Pycnoporus sanguineus, conhecido popularmente como orelha-de-pau, pode ser encontrado na madeira, onde após instalado é capaz de

\footnotetext{
${ }^{1}$ Doutoranda em Engenharia Florestal. UFSM - Universidade Federal de Santa Maria. Av. Roraima, 1000 - Camobi 97105-900 - Santa Maria, RS, Brasil. E-mail: amandagrassmann@gmail.com

2Professor Titular do Departamento de Engenharia Florestal. UFSM - Universidade Federal de Santa Maria. Av. Roraima, 1000 - Camobi - 97105-900 - Santa Maria, RS, Brasil. E-mail: eliosantini@smail.ufsm.br

3 Professor Adjunto do Departamento de Engenharia Florestal. UFSM - Universidade Federal de Santa Maria / FW - Campus Frederico Westphalen. BR386 - Km40 - Linha 7 de Setembro s/n - 98400-000 - Frederico Westphalen, RS, Brasil. E-mail: stelamk@terra.com.br; romulo_trevisan@ufsm.br
} 
hidrolisar a celulose, a hemicelulose e a lignina resultando em alterações nas propriedades físicas e mecânicas desse material (ROWELL, 2012). Dessa forma, tendo em vista os prejuízos que a decomposição biológica pode causar na produção madeireira, o emprego de substâncias preservantes torna-se compulsório, pois é uma das mais eficientes alternativas de evitar o ataque desse e de outros organismos xilófagos (BROCCO et al. 2017; HSU et al., 2007).

Atualmente os tratamentos tradicionais, de acordo com Kartal et al. (2015), utilizam o CCA (arseniato de cobre cromatado) ou CCB (borato de cobre cromatado). Porém, esses produtos industriais são tóxicos aos seres humanos, aos organismos não xilófagos e são compostos por metais como cobre, cromo, zinco, arsênio, boro e flúor, além de complexos como creosoto e aminas (ZHANG et al., 2016). Dessa forma, há uma crescente necessidade de inovação tecnológica em produtos antifúngicos eficazes e que não agridam o meio ambiente (GONZÁLEZ-LAREDO et al., 2015; MACHADO et al., 2006).

Uma possível solução pode ser encontrada na própria natureza, visto que as plantas produzem diversos compostos orgânicos, denominados de metabólitos secundários, que possuem direta associação com a relação planta/meio ambiente (SIMÕES et al., 2007). Algumas espécies arbóreas possuem natural resistência a diversos organismos deterioradores por produzirem compostos polifenólicos, flavonóides, lignanas, estilbenos e taninos (GAO et al., 2006; LIIMATAINEN et al., 2012; RAMÍREZ et al. 2012; SMEDS et al., 2011; ZHANG et al., 2016); ou seja, a presença dessas substâncias na madeira está relacionada com um aumento na vida útil do material (MAKINO et al., 2011; YAO et al., 2010).

O tanino, por exemplo, já é um produto explorado pela indústria do couro devido a sua capacidade de isolar fibras naturais contra fungos e bactérias que são as principais responsáveis pela deterioração da pele animal (CANNAS, 2011). Comprovada a toxidez dos componentes químicos desses produtos naturais, os mesmos podem ser aplicados no controle de fungos fitopatógenos (KIRKER et al., 2013; SILVA; BASTOS, 2007).

A utilização de extratos botânicos para elevar a durabilidade de madeiras propensas ao apodrecimento é vista como uma alternativa, a fim de promover a utilização de produtos ecológicos na indústria de tratamento de madeira (ASAMOAH et al., 2011; KIRKER et al., 2013; SYOFUNA et al., 2012).

Esse estudo fundamenta-se na investigação de alternativas para encontrar a melhor forma de utilizar o extrativo tanino, considerando a falta de informações consistentes de tal produto, examinando o seu comportamento com altas temperaturas em meio de cultura e, principalmente, o seu grau de toxidez ao fungo causador da podridão branca. Assim, o presente trabalho tem como principal objetivo analisar a atividade antifúngica do extrato natural da acácia-negra à Pycnoporus sanguineus.

\section{MATERIAL E MÉTODOS}

Para a realização do experimento o extrato natural de acácia negra foi fornecido pela empresa Sociedade Extrativa Tanino de Acácia - SETA S.A., situada no município de Estância Velha/RS. Já a colônia com fragmentos do fungo de podridão branca, Pycnoporus sanguineus, foi cedida pelo Setor de Biodegradação e Preservação da Madeira - LPF/ IBAMA.

O meio de cultura utilizado foi batata-dextrose-ágar (BDA) por ser considerado universalmente indicado para o crescimento da maioria dos fungos (ALFENAS; MAFIA, 2007). O fungo foi repicado para placas de Petri contendo BDA para conservação dos isolados em ambiente refrigerado a $10^{\circ} \mathrm{C}$ e multiplicado conforme a metodologia de Santos et al. (2009).

A fim de investigar a metodologia ideal para solubilizar e tornar a solução de tanino compatível com o meio de cultura, foram realizados, inicialmente, três procedimentos de preparo: (1) esterilizando o tanino junto ao meio, (2) realizando filtragem a vácuo e (3) não esterilizando o tanino.

No primeiro método analisado o produto foi adicionado antes do meio de cultura ser autoclavado. No segundo, o tanino passou por um processo de filtragem com o auxílio de uma bomba de vácuo, adicionando-o ao BDA após o mesmo ter sido esterilizado. Já no terceiro procedimento elaborado, o extrativo, sem passar pela filtragem, foi misturado ao meio após a esterilização, ou seja, depois do BDA ser autoclavado.

Para realização dessa primeira etapa o experimento foi composto pelo tratamento testemunha e por quatro concentrações do produto: 5, 10, 15 e 20 g. $\mathrm{L}^{-1}(0,5 ; 1,0 ; 1,5$ e 2,0\%, respectivamente), 
que foram individualmente incorporadas ao meio de cultura e então vertidos em placas de Petri, formando um total de 10 placas por tratamento. Logo após, cada placa recebeu um disco de $6 \mathrm{~mm}$ de diâmetro contento micélio, sendo então levadas para a BOD e incubadas por, aproximadamente, 7 dias ou até que a testemunha preenchesse a primeira placa. O ambiente manteve-se climatizado a $25^{\circ} \mathrm{C}, 75 \pm 5 \%$ de UR e com fotofase de 12 horas.

O efeito do tanino foi avaliado por meio de mensurações diárias do crescimento micelial do fungo P. sanguineus as quais tiveram início 24 horas após a inoculação e corresponderam à média de duas medidas diametralmente opostas da colônia fúngica. Em seguida, o índice de crescimento micelial (ICM) ou taxa de crescimento (TC) foi calculado pela fórmula adaptada por Salgado et al. (2003).

Para analisar a primeira etapa do experimento utilizou-se o delineamento experimental inteiramente casualizado (DIC), com 10 repetições em esquema bi fatorial 5x3, sendo 5 doses e 3 metodologias. Dessa forma, o índice de crescimento micelial (ICM) ou taxa de crescimento (TC) calculados foram submetidos à análise de variância para verificar a existência de diferenças significativas pelo teste de t, com o auxílio do software estatístico Genes (CRUZ, 2001). A avaliação das doses, por se tratar de um fator quantitativo, foi realizada pela análise de regressão.

Na segunda etapa do experimento foi realizado o teste fungitóxico com concentrações maiores, de 30,40 e 50 g. $\mathrm{L}^{-1}(3,0 ; 4,0$ e 5,0\%, respectivamente), utilizando somente a metodologia que foi avaliada como ideal no primeiro estudo - tanino não esterilizado, buscando, dessa forma, melhores resultados.

Nessa etapa o arranjo experimental também foi em DIC, porém composto por 4 tratamentos (incluindo a testemunha) e 10 repetições. As médias do índice de crescimento micelial (ICM) ou taxa de crescimento (TC) calculadas foram comparadas pelo teste de Tukey a 5\% de probabilidade de erro utilizando o mesmo pacote estatístico.

\section{RESULTADOS E DISCUSSÃO}

Nos resultados da primeira etapa do experimento, a análise da variância demonstrou significância do índice de crescimento micelial tanto para doses quanto para os métodos avaliados. Na Tabela 1 verifica-se diferenças entre as concentrações utilizadas e nas metodologias adotadas, apresentando também efeito de interação entre doses e métodos na taxa de crescimento.

Tabela 1. Valores médios do índice de crescimento micelial obtidos nos métodos avaliados.

Table 1. Mean values of mycelial growth index obtained in the evaluated methods.

\begin{tabular}{cccc}
\hline Dose (\%) & Tanino esterilizado & Filtragem à vácuo & Tanino não esterilizado \\
\hline 0,0 & $51,49 \mathrm{eB}^{*}$ & $40,9 \mathrm{dA}$ & $43,42 \mathrm{dA}$ \\
0,5 & $36,33 \mathrm{~dB}$ & $35,68 \mathrm{cAB}$ & $33,23 \mathrm{cA}$ \\
1,0 & $29,38 \mathrm{cA}$ & $26,30 \mathrm{bA}$ & $27,31 \mathrm{bA}$ \\
1,5 & $23,21 \mathrm{bB}$ & $24,22 \mathrm{abB}$ & $16,73 \mathrm{aA}$ \\
2,0 & $16,36 \mathrm{aA}$ & $22,18 \mathrm{aB}$ & $15,53 \mathrm{aA}$ \\
\hline
\end{tabular}

*Médias seguidas pela mesma letra maiúscula na linha e minúscula na coluna não diferem entre si pelo teste $t$ à $5 \%$ de probabilidade

A partir dos valores do ICM, os dados foram analisados estatisticamente pelo desdobramento do efeito da interação, ou seja, cada método avaliado individualmente dentro de cada dose. O método que emprega o tanino não esterilizado se mostrou mais eficiente, diferindo na maioria das doses das demais metodologias. Em todas as doses essa metodologia foi estatisticamente igual (doses $0 \mathrm{e}$ $1 \%$ ) ou superior (doses 0,$5 ; 1,5$ e 2\%) aos demais métodos testados. Assim, essa diferença permite afirmar que o tanino não esterilizado traz benefícios à inibição do crescimento micelial do $P$. sanguineus, visto que apresentou os melhores resultados de ICM.

A menor eficiência do tanino esterilizado, onde o produto foi submetido a um processo de superaquecimento junto ao meio de cultura, provavelmente está associada a alteração da sua composição original. Conforme Borsato et al. (2008), algumas substâncias importantes podem volatilizar ou alterar suas características em virtude da longa exposição a altas temperaturas. Com relação ao método onde o produto passou pelo processo de filtragem à vácuo, possivelmente teve nesse retida alguma substância importante da composição do tanino.

Ao analisar o efeito das concentrações foram observadas taxas variáveis de inibição do crescimento micelial do fungo P. sanguineus pelo extrativo tanino. Entretanto, de maneira geral, houve 
uma tendência decrescente do ICM com a dose aplicada, ou seja, à medida que aumentou a concentração do extrato ocorreu inibição do crescimento micelial do fungo (Figura 1).
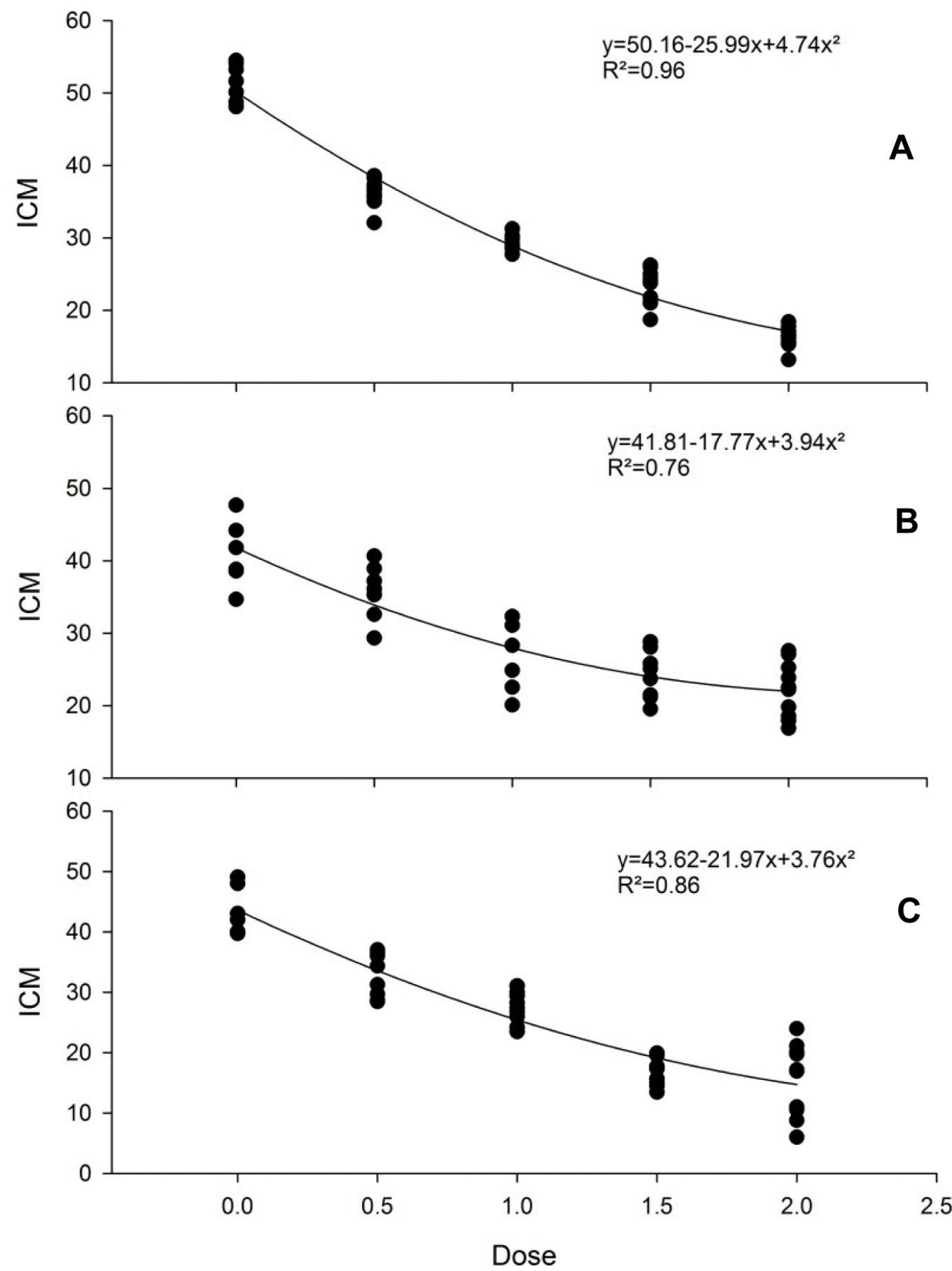

Figura 1. Índice de crescimento micelial de Pycnoporus sanguineus em função da concentração de extrato tânico (A-tanino esterilizado, B-filtrado, C-não esterilizado).

Figure 1. Mycelial growth index of Pycnoporus sanguineus depending on the concentration of tannic extract (A-sterile tannin, B- tannin filtered, C-non-sterile).

Na Figura 1 evidencia-se que o ICM da testemunha (sem extrato) obteve valores entre 31,05 e 54,49 enquanto no tratamento onde foram adicionados $0,5 \%$ de tanino, o mesmo reduziu para a faixa de 29,34 e 49,70. Variações semelhantes foram observadas para as concentrações de 1,0\% (valores médios de ICM entre 20,09 e 44,99), 1,5\% (ICM médio entre 13,44 e 39,9) e, na dosagem de $2,0 \%$, onde a inibição mostrou-se ainda maior, apresentando os menores índices de crescimento, entre 6 e 27,59 .

A redução do ICM nos diferentes métodos e concentrações de tanino foi observada visualmente após a execução do experimento, conforme demonstra a Figura 2. 

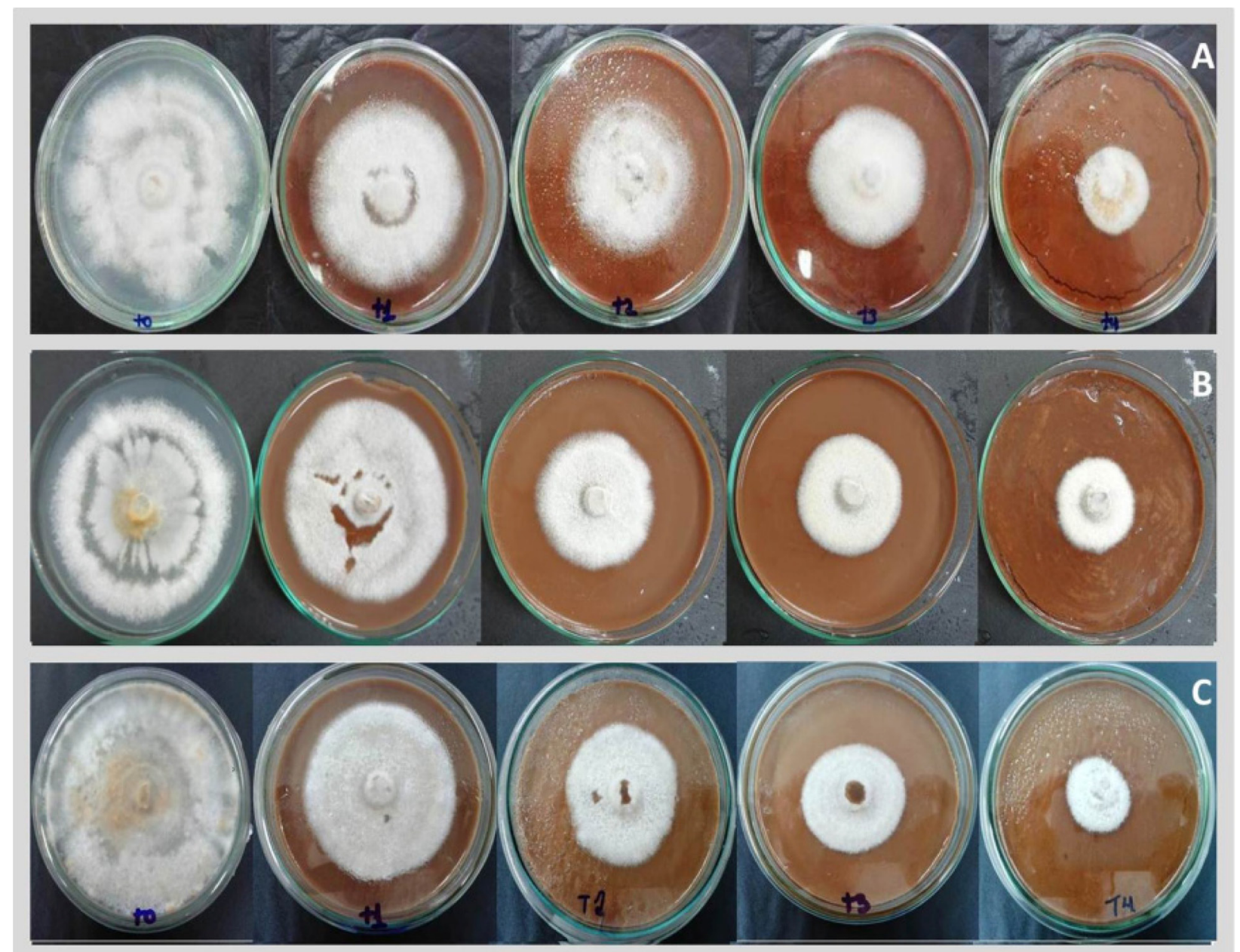

Figura 2. Avaliação visual do crescimento micelial: esterilizado (A), filtrado (B) e não esterilizado (C). As concentrações estão dispostas da esquerda para direita, de maneira crescente, iniciando pela testemunha e seguida pelas concentrações de 0,$5 ; 1,0 ; 1,5$ e $2,0 \%$.

Figure 2. Visual assessment of mycelial growth: sterile (A), filtered, (B) and non-sterile (C) The concentrations increased from left to right, increasingly, beginning with the control and followed by the concentrations of $0.5 ; 1.0 ; 1.5$ and $2.0 \%$.

Ao analisar a Figura 2 verifica-se que o potencial tóxico do extrativo a P. sanguineus foi visível uma vez que, enquanto a testemunha preencheu completamente a placa em aproximadamente sete dias, os tratamentos contendo o extrativo tiveram um crescimento reduzido. Essa constatação foi observada desde a menor concentração $(0,5 \%)$ tornando-se ainda mais expressiva com o aumento das doses.

Resultados relatando a toxidez do extrato tânico também foram descritos por Anttila et al. (2013), onde frações de tanino extraídas de cones de coníferas inibiram o crescimento de fungos de podridão parda em culturas de meio líquido em baixas concentrações $\left(0,25-0,5 \mathrm{~g} \mathrm{~L}^{-1}\right)$. No entanto, para a inibição de fungos de podridão branca, os autores relataram a necessidade de concentrações mais altas $\left(1,25-1,75 \mathrm{~g} \mathrm{~L}^{-1}\right)$, situação contrária à encontrada no presente trabalho, onde verificou-se poder inibitório do extrato tânico sobre P. sanguineus desde as concentrações mais baixas testadas $\left(0,5 \mathrm{~g} \mathrm{~L}^{-1}\right)$.

Para a realização da segunda etapa do experimento e assim determinar a dose do extrato capaz de inibir completamente o crescimento do organismo deteriorador, o método com o tanino não esterilizado, avaliado como mais adequado no estudo inicial, foi empregado. Os resultados evidenciaram a mesma tendência da primeira parte da investigação, onde as maiores concentrações reduziram gradativamente o desenvolvimento do fungo (Tabela 2).

O extrato demonstrou maior grau de toxidez com o aumento das concentrações, de modo que enquanto a testemunha apresentou ICM médio de 53,79, diferindo de todos os demais, no mesmo período a dose de 30 g. $\mathrm{L}^{-1}$ teve uma redução do crescimento de $69,44 \%$ em relação ao tratamento sem produto. Quando adicionado 40 g.L.- esse percentual subiu para $89,12 \%$, que só é numericamente inferior a dose de 50 g. $\mathrm{L}^{-1}$, a qual inibiu $93,6 \%$ do desenvolvimento micelial quando comparada a testemunha (Figura 3). 
Tabela 2. Comparação das médias dos tratamentos $0,3,4$ e $5 \%$.

Table 2. Comparison of the means of the treatments $0,3,4$ and $5 \%$.

\begin{tabular}{cc}
\hline Concentração (\%) & Índice de Crescimento Micelial \\
\hline 0 & $53,79 \mathrm{c}^{*}$ \\
3 & $16,45 \mathrm{~b}$ \\
4 & $5,86 \mathrm{a}$ \\
5 & $3,45 \mathrm{a}$ \\
\hline
\end{tabular}

* Médias seguidas pela mesma letra não diferem entre si pelo Teste de Tukey à $5 \%$ de probabilidade.

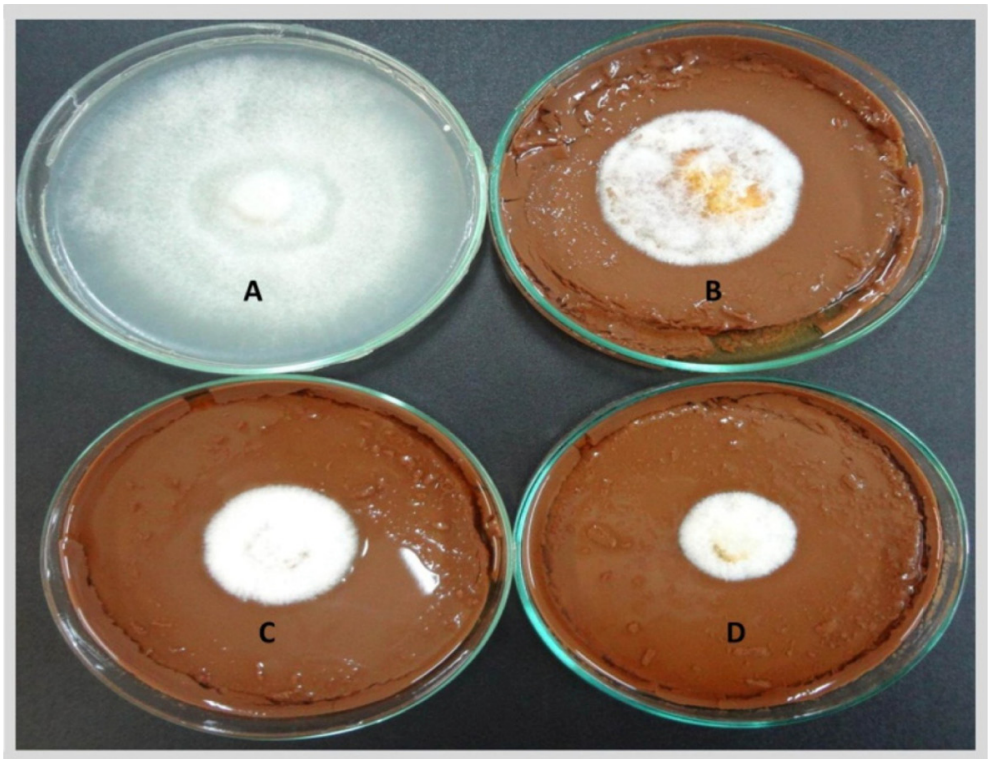

Figura 3. Avaliação visual das concentrações testadas: placa testemunha (A), 3\% (B), 4\% (C) e 5\% (D).

Figure 3. Visual assessment of the concentrations tested: control plate (A), 3\% (B), 4\% (C) and 5\% (D).

De outra forma, o aumento da concentração do extrato tânico também revelou a incompatibilidade do produto com o ágar, substância responsável por deixar o meio de cultura gelatinoso (Figura 3). Entretanto, tal situação não comprometeu os resultados, alterando somente o aspecto visual das placas com maiores concentrações do produto.

Embora as doses de 4 e 5\% não tenham apresentado diferença entre suas médias, o maior grau de inibição total por placa foi na maior concentração, a qual impediu completamente o crescimento micelial em $50 \%$ das unidades experimentais testadas (Figura 4).

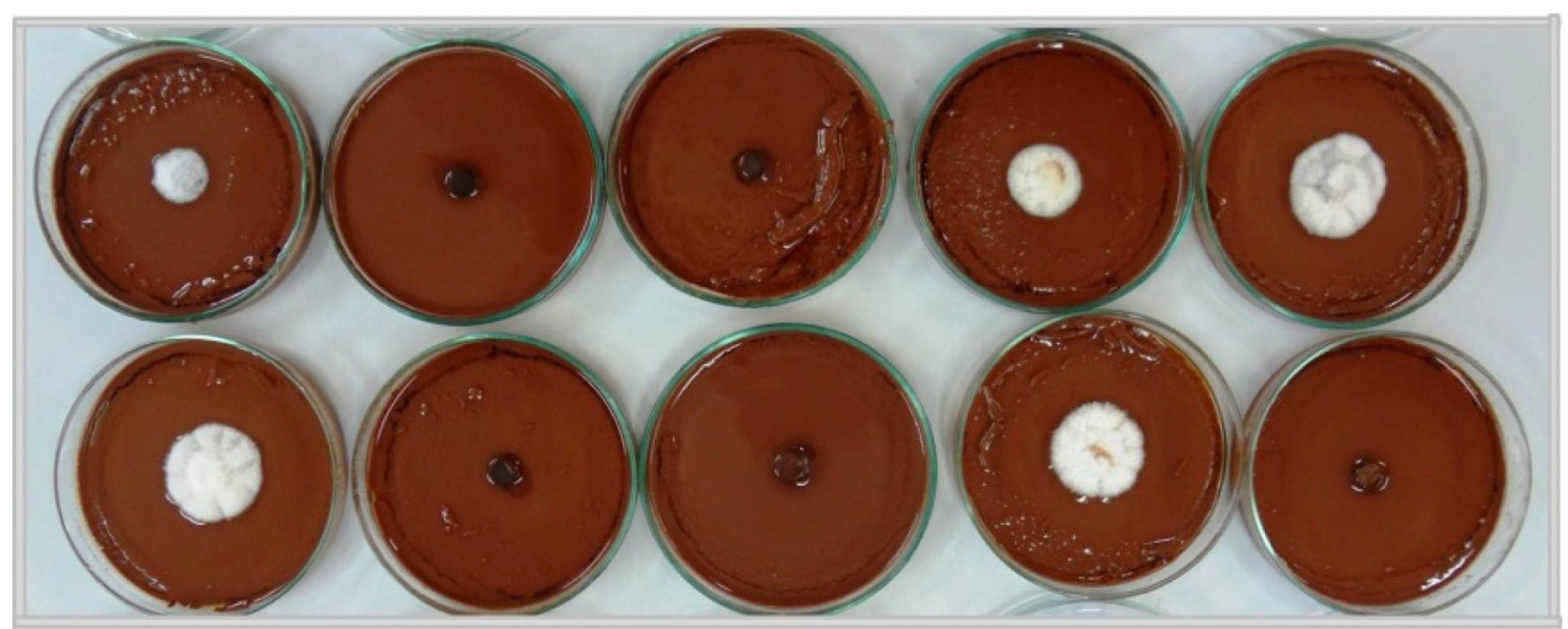

Figura 4. Inibição do crescimento micelial nas repetições da concentração de $5 \%$.

Figure 4. Inhibition of mycelial growth in repetitions of $5 \%$ concentration.

Dessa maneira, ficou evidente que quanto maior a dose de extrativo, menor o vigor de crescimento do fungo. O mecanismo da toxidez do tanino é explicado por Leinmüller et al. (1991) como a capacidade do produto em precipitar proteínas e interagir com outras macromoléculas, como car- 
boidratos, membrana celular das bactérias e íons metálicos, inibindo dessa forma as enzimas dos fungos e reduzindo seu crescimento.

Em estudo semelhante, o extrato tânico obtido do mesocarpo de coco mostrou baixo efeito contra o crescimento do fungo Trametes versicolor, onde somente a combinação da substância com sais de cobre mostraram resultados satisfatórios (RAMÍREZ et al. 2012). Uma possível explicação encontrada por Arras e Grella (1992) seria de que uma mesma espécie de planta pode dar origem a uma variedade de extratos, com diferentes composições e bioatividades. Devido a isso, afigura-se mais fidedigno a utilização de produtos industrializados, com pureza conhecida, mais estáveis, consistentes e com melhor relação custo/benefício.

Os cones e cascas de coníferas são considerados como uma fonte de extração de taninos com potencial na proteção de madeiras. No entanto, as chances para a utilização industrial de tais extratos são baixas, pois o processo de purificação tornaria o custo de produção elevado (ANTTILA et al. 2013). Devido ao extrato de acácia-negra já ser um produto comercial utilizado no curtimento de peles de animais, torna-se vantajosa a sua aplicação também na preservação de madeiras pelo fato de não ser necessário adicionar nenhum processo específico na sua fabricação e já ser produzido em larga escala (TASCIOGLU et al., 2013).

\section{CONCLUSÕES}

1. A melhor forma de avaliar a eficácia do tanino em meio de cultura foi utilizando o método não esterilizado, ou seja, adicionando-o após a autoclavagem do meio.

2. O extrato tânico possui potencial tóxico ao fungo Pycnoporus sanguineus.

3. As concentrações de 4 e $5 \%$ foram as mais eficientes sobre a atividade fúngica, sendo que a segunda inibiu $50 \%$ das placas avaliadas, apresentando também o menor índice de crescimento micelial dentre todos os tratamentos testados.

\section{REFERÊNCIAS BIBLIOGRÁFICAS}

ALFENAS, A. C.; MAFIA, R. G. Métodos em fitopatologia. Viçosa: Editora UFV, 2007. 382 p.

ANTTILA, A. K.; PIRTTILA, A. M.; HAGG,AM, H.; TIITTO, R. J. Condensed conifer tannins as antifungal agents in liquid culture. Holzforschung, Berlin, v. 67, n. 7, p. 825-832, 2013.

ARRAS, G.; GRELLA, G. E. Wild thyme, Thymus capitatus essential oil seasonal changes and antimycotic activity. Journal of Horticultural Science, v. 67, n. 2, p. 197-202, 1992.

ASAMOAH, A.; FRIMPONG-MENSAH, K.; ANTWI-BOASIAKO, C. Efficacy of Tectona grandis (Teak) and Distemonanthus benthamianus (Bonsamdua) water extractives on the durability of five selected ghanaian less used timber species. Pakistan Journal of Chemistry, v. 1, n. 1, p. 28-31, 2011.

BORSATO, A. V.; DONI-FILHO, L.; CÔCCO, L. C.; PAGLIA, E. C. Rendimento e composição química do óleo essencial da camomila <[i>Chamomilla recutita (L.) Rauschert] extraído por arraste de vapor d'água, em escala comercial. Ciências Agrárias, Londrina, v. 29, n. 1, p. 129-136, 2008.

BROCCO, V. F.; PAES, J. B.; COSTA, L. G.; ARANTES, M. D. C. Potential of teak heartwood extracts as a natural wood preservative. Journal of Cleaner Production, v.142, N. 4, p. 2093-2099, 2017.

CANNAS, A. Tannins: Fascinating but Sometimes Dangerous Molecules. Cornell: Cornell University, 2011. Disponível em < http://www.ansci. cornell.edu/plants/toxicagents/tannin.html >. Acesso em: 25 out. 2015.

CRUZ, C.D. Programa Genes: Aplicativo computacional em genética e estatística. Viçosa: Editora UFV, 2001. 648 p.

GAO, H.; SCHUPE, T. F.; EBERHARDT, T. L.; HSE, C. Y. Antioxidant activity of extracts from the bark of Chamaecyparis lawsoniana (A. Murray) Parl. Holzforschung, Berlin, v. 60, n. 4, p. 459-462, 2006. 
Silveira et al. - Atividade antifúngica do extrato natural da acácia-negra à Pycnoporus sanguineus

HSU, F. L.; CHANG, H.T.; CHANG, S. T. Evaluation of antifungal properties of octyl gallate and its synergy with cinnamaldehyde. Bioresource Technology, Essex, v. 98, n. 4, p. 734-738, 2007.

KIRKER, G.T.; BLODGETT, A. B.; ARANGO, R. A.; LEBOW, P. K.; CLAUSEN, C. A. The role of extractives in naturally durable wood species. International Biodeterioration \& Biodegradation, v. 82, p. 53-58, 2013.

GONZÁLEZ-LAREDO, R. F. Wood preservation using natural products. Madera y Bosques, Cidade do México, v. 21, p. 63-76, 2015.

KARTAL, S. N.; TERZI, E.; YILMAZ, H.; GOODELL, B. Bioremediation and decay of wood treated with ACQ, micronized ACQ, nano-CuO and CCA wood preservatives. International Biodeterioration \& Biodegradation, Birmingham, v. 99, p. 95-101, 2015.

LEINMÜLLER, E.; STEINGASS, H.; MENKE, K. H. Tannins in ruminant feedstuffs. Animal Research and Development, Queensland, v.33, p.9-62, 1991.

LIIMATAINEN, J.; KARONEN, M.; SINKKONEN, J. HELANDER, M.; SALMINEN, J. P. Characterization of phenolic compounds from inner bark of Betula pendula. Holzforschung, Berlin, v. 66, n. 2, p.171-181, 2012.

MAKINO, R.; OHARA, S.; HASHIDA, K. Radical scavenging characteristics of condensed tannins from barks of various tree species compared with quebracho wood tannin. Holzforschung, Berlin, v. 65, n.5, p. 651-657, 2011.

MACHADO, G. O.; CALIL JÚNIOR, C.; POLITO, W.; PAWLICK, A. Preservante natural de madeira para uso na construção civil - óleo de neem. Minerva, São Paulo, v. 3, n. 1, p.1-8, 2006.

ROWELL, R. M. Handbook of wood chemistry and wood composites. Madison: CRC press, 2012.

RAMÍREZ, M. G. L.; RUIZ, H. G. O.; ARZATE, F. N.; GALLEGOS, M. A. C.; ENRIQUEZ, S. G. Evaluation of fungi toxic activity of tannins and a tannin-copper complex from the mesocarp of Cocos nucifera Linn. Wood Fiber Science, Hanover, v. 44, n. 4, p. 357-364, 2012.

SAlGADO, A. P. S. P.; CARDOSO, M. G.; SOUZA, P. E.; SOUZA, J. A.; ABREU, C. M. P.; PINTO, J. E. B. P. Avaliação da atividade fungitóxica de óleos essenciais de folhas de Eucalyptus sobre Fusarium oxysporum, Botrytiscinerea e Bipolares sorokiniana. Ciência e Agrotecnologia, Lavras, n. 27, n. 2, p. 249-254, 2003.

SANTOS, F. J.; FERREIRA, J. M. S.; RIBEIRO, V. J. O.; OLIVEIRA, A. C. L.; AZEVEDO, A. G. C. Protocolo para produção massal de fungos entomopatogênico. Empresa brasileira de pesquisa agropecuária. Boletim de pesquisa e desenvolvimento, Colombo, v. 43, 2009. 24 p.

SILVA, D. M. H.; BASTOS, C. N. Atividade antifúngica de óleos essenciais de espécies de Piper sobre Crinipellis perniciosa, Phytophthora palmivora e Phytophthora capsici. Fitopatologia Brasileira, Brasília, v.32, n. 2, p. 143145, 2007.

SIMÕES C. M. O; SCHENKEL, E.P.; GOSMANN, G.; MELLO, J.C.P.; MENTZ, L.A.; PETROVICK. P.R. Farmacognosia: da Planta ao Medicamento. Florianópolis: Editora UFSC, 2007. 821 p.

SMEDS, A.I; EKLUND, P. C.; MONOGIUDI, E.; WILFFOR, S. M. Chemical characterization of polymerized products formed in the reactions of matairesinol and pinoresinol with the stable radical 2,2-diphenyl-1picrylhydrazyl. Holzforschung, Berlin, v.66, n. 3, p.283-294, 2011.

SYOFUNA, A.; BANANA, A.Y.; NAKABONGE, G. Efficiency of natural wood extractives as wood preservatives against termite attack. Maderas: Ciencia y Tecnología, Concepcion, v.14, n. 2, p.155-163, 2012. 
TASCIOGLU, C.; YALCIN, M.; SEN, S.; AKCAY, C. Antifungal properties of some plant extracts used as wood preservatives. International Biodeterioration \& Biodegradation, Birmingham, v. 85, p. 23-28, 2013.

YAO, L. N.; SU, Y. F.; YIN, Z. F.; QIN, N.; LI. T. X.; SI, C. L.; LIU, E. W.; GAO, X. M. A new phenolic glucoside and flavonoids from the bark of Eucommia ulmoides Oliv. Holzforschung, Berlin, v. 64, n. 5, p. 571-575, 2010.

ZHANG, Z.; YANG, T.; MI, NA; XIE, Y. J. Antifungal activity of monoterpenes against wood white-rot fungi. International Biodeterioration \& Biodegradation, Birmingham, v. 106, p. 157-160, 2016. 
